\title{
MONITORAMENTO DO USO E OCUPAÇÃO DO SOLO EM ÁREA DE INFLUÊNCIA DO MUNICÍPIO DE FAZENDA RIO GRANDE - REGIÃO METROPOLITANA DE CURITIBA-PR
}

\section{Environment monitoring of the use and occupation of the soil in area of influence in the municipality of Fazenda Rio Grande - region metropolitan of Curitiba-PR.}

\author{
Valter Antonio Becegato1, \\ Francisco José Fonseca Ferreira², \\ João Batista Pereira Cabral ${ }^{3}$, \\ Olívia Aparecida Rodolfo Figueiredo ${ }^{4}$, \\ Sílvio Luís Rafaeli Neto 5
}

\section{RESUMO}

Objetivou-se com este trabalho, monitorar o uso e a ocupação do solo rural e urbano do município de Fazenda Rio Grande região metropolitana de Curitiba-PR, utilizando-se fotografias aéreas dos anos de 1952, 1962, 1980, 1996, e imagens do satélite TM-Landsat ano 2001 bandas 3, 4 e 5 . Foram identificadas as seguintes classes temáticas: mata, mata de várzea, campo, mineração na várzea, várzea, agricultura de várzea, área urbana e reflorestamento. Ao longo de 49 anos, houve grande alteração da ocupação urbana que não existia em 1952, praticamente inexpressiva em 1962, com forte ocupação espacial no intervalo de 1980 a 2001. As áreas agrícolas concentram-se principalmente sobre os argissolos, inseridos espacialmente nas partes mais declivosas da paisagem.

Palavras chave:

Fotografias aéreas, uso do solo, meio ambiente

\section{ABSTRACT}

The use and occupation of soil in the municipality of Fazenda Rio Grande, in the Curitiba-PR Metropolitan Area, were evaluated by photo interpretation and satellite image interpretation. Aerial photographs of 1952, 1962, 1980,1996, orthophotochart of 1980 and TM-Landsat/5 satellite images of 2001, bands 3 , 4 , and 5 were used. A vast drain network occupies the region, where soils such as Oxisols are in the plains and Ultisols are in the more inclined areas. The following thematic classes were identified: forest, swamp forest, field, swamp mining, swamp, swamp agriculture, urban area, and reforestation. Along 49 years, there was a large alteration of the urban occupation, which did not exist in 1952, practically did not exist in 1962, with significant occupation during the period from 1980 to 2001 .

Key words:

Aerial photographs, soil use, environment

\footnotetext{
1 Engenheiro Agrônomo - Professor Doutor UDESC/CAV.

2 Geólogo - Doutor Professor- UFPR.

3 Geógrafo - Professor Doutor - UFGO.

4 Química - Professora M.Sc.- UDESC/CAV.

5 Engenheiro Agrônomo - Doutor Professor - UDESC/CAV.
} 
BECEGATO, V. A.; MACIEL, M. M.; CABRAL, J. B. P.; CARDOSO, C. O.; SOCCOL, J. O. Monitoramento ambiental do uso e...

\section{INTRODUÇÃO}

Grande atenção tem sido dado ao uso do solo e a suas implicações econômicas, sociais e ambientais. A crescente demanda de alimentos em razão do crescimento demográfico leva a utilização cada vez mais intensiva do solo. Considerando que a curto prazo o solo é um recurso natural não renovável, ele precisa ser utilizado de forma sustentável para que este recurso não se esgote.

Uma das constatações mais preocupantes está ligada ao uso e ocupação do solo em regiões metropolitanas, pela rápida expansão urbana, implicando em sérios problemas ambientais. A região metropolitana de Curitiba assim como outras do Brasil, merecem por parte de seus governantes, uma política efetiva de monitoramento periódico, para que não se perca o controle das ocupações irregulares, principalmente em áreas de mananciais.

Densa rede de drenagem cobre a área (Figura 1), representada por um coletor mestre, o Rio Iguaçú, que corta a região no sentido Leste para Oeste, e seus tributários. O relevo é aplainado no conjunto, porém no detalhe mostra feições de moderamente acidentado e partes de relevo fortemente ondulado (MAACK, 1981).
O padrão de drenagem é do tipo dendrítico, cujo modelo se forma na presença de rochas que oferecem resistência uniforme na horizontal. O tipo de drenagem desenvolvido em um terreno é em parte função da relação infiltração/deflúvio, que por sua vez está ligada as propriedades físicas do solo, de tal modo que uma drenagem superficial escassa é indicativa de alta infiltração e boa permeabilidade (GARCIA, 1982).

A modificação rápida do uso do meio físico, decorrente da intensificação tanto para uso agrícola como para áreas urbanas, requer a adoção de técnicas de avaliação e de diagnóstico que acompanhem a dinâmica espaço-temporal do uso do solo (ASSAD, 1995 e CANEPARO, 2000). As mais importantes feições reconhecidas dos materiais terrestres através das fotografias aéreas são: relevo, drenagem, erosão, coloração do solo, vegetação e uso da terra, sendo elementos essenciais que levam ao entendimento do que não se vê, mas está indicado pelas combinações das mesmas. A associação de métodos usando dados coletados de fotografias aéreas e dados obtidos a campo é eficaz para confecção de mapas temáticos, utilizando-se técnicas de classificação multiespectral supervisionada e a interpretação visual direta sobre os fotogramas (EKSTRAND, 1986).

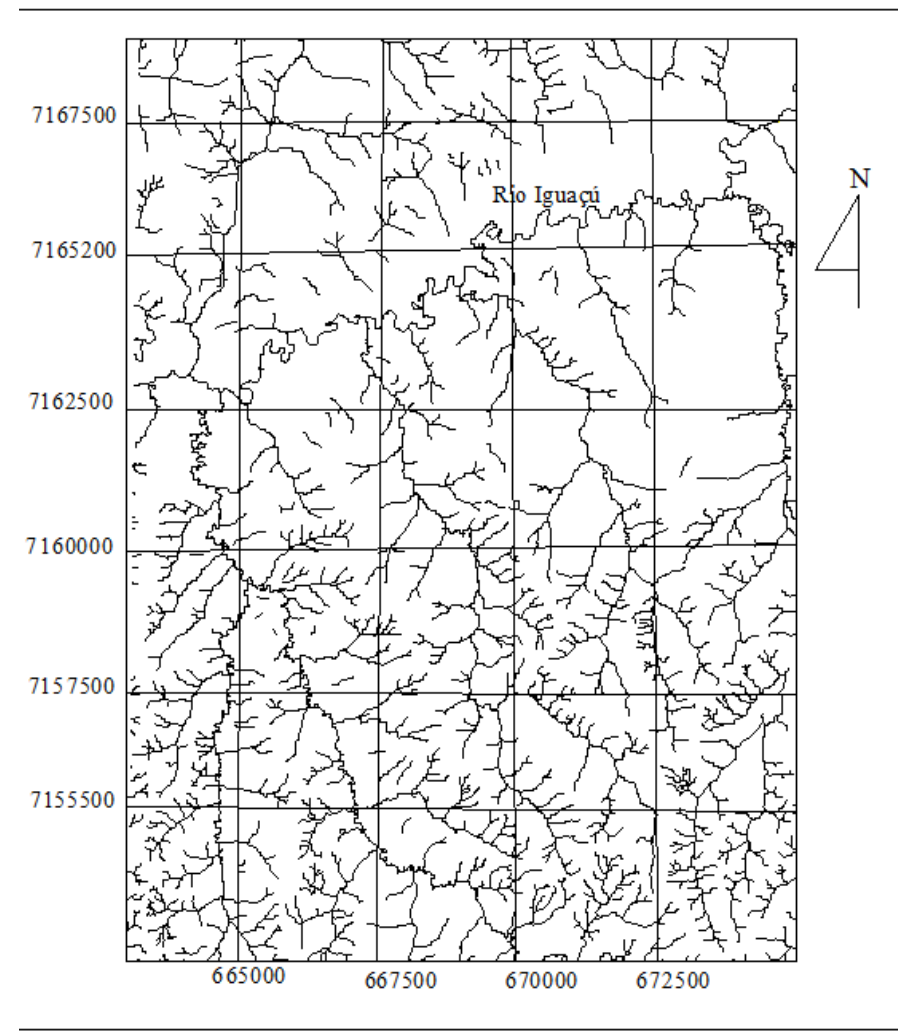

Figura 1. Rede de drenagem. 
BECEGATO, V. A.; MACIEL, M. M.; CABRAL, J. B. P.; CARDOSO, C. O.; SOCCOL, J. O. Monitoramento ambiental do uso e...

O uso de produtos orbitais em estudos ambientais, cuja temática é fisiografia e morfologia do relevo, é amplamente utilizado, principalmente como subsídio aos estudos de cobertura vegetal, uso do solo e ocupação (VEDONELLO \& MATTOS, 1991).

DANGERMOND (1987) e ARONOF (1993), observam que há duas classes de estrutura de dados para representação geográfica, têm sido usadas para armazenar e representar a informação espacializada em formato digital: a estrutura vetorial e a matricial ou raster. Para BURROUGH (1986), a representação vetorial de um objeto é a tentativa de representá-lo o mais exatamente possível. Supõe-se que o espaço de coordenadas é contínuo e não quantizado como no espaço matricial, permitindo que sejam definidas com boa precisão todas as posições, componentes e dimensões.

O trabalho objetivou estudar, representar e quantificar o uso e ocupação dos solos pela atividade antrópica em nível urbano e rural, com dados obtidos de fotografias aéreas em diferentes datas e imagens de satélite TM-Landsat/5 ano 2001, utilizando-se sistemas de informações georreferenciadas.

\section{MATERIAL E MÉTODOS}

\section{Caracterização geral da área}

A área de pesquisa está localizada entre as coordenadas UTM $E=663000 \mathrm{~m}$ e $\mathrm{N}=7152800 \mathrm{~m}$ e $\mathrm{E}=675000 \mathrm{~m}$ e $\mathrm{N}=7169000 \mathrm{~m}$ do meridiano central 510 WGR (Figura 2). Segundo MAACK (1953), a porção sudoeste do primeiro planalto do Paraná está constituída litologicamente por gnaisses e migmatitos granitizados do complexo cristalino, rochas associadas aos migmatitos como xistos magnesianos, anfibólios e quartzitos, sedimentos pleistocênicos da "formação Guabirotuba". Conforme (MINEROPAR, 1989), ocorrem depósitos holocênicos nas planícies aluviais principalmente ao longo do Rio Iguaçu. BIGARELLA \& SALAMUNI (1962), utilizaram o termo "formação Guabirotuba" para designar os sedimentos pleistocênicos da bacia de Curitiba.

Segundo EMBRAPA (1984), a vegetação primária da região é classificada como floresta subtropical perenifólia, apresentado três níveis: o nível superior constituído por araucárias, imbuia, cedro, canela e outras espécies folhosas de grande porte, o nível médio é composto por

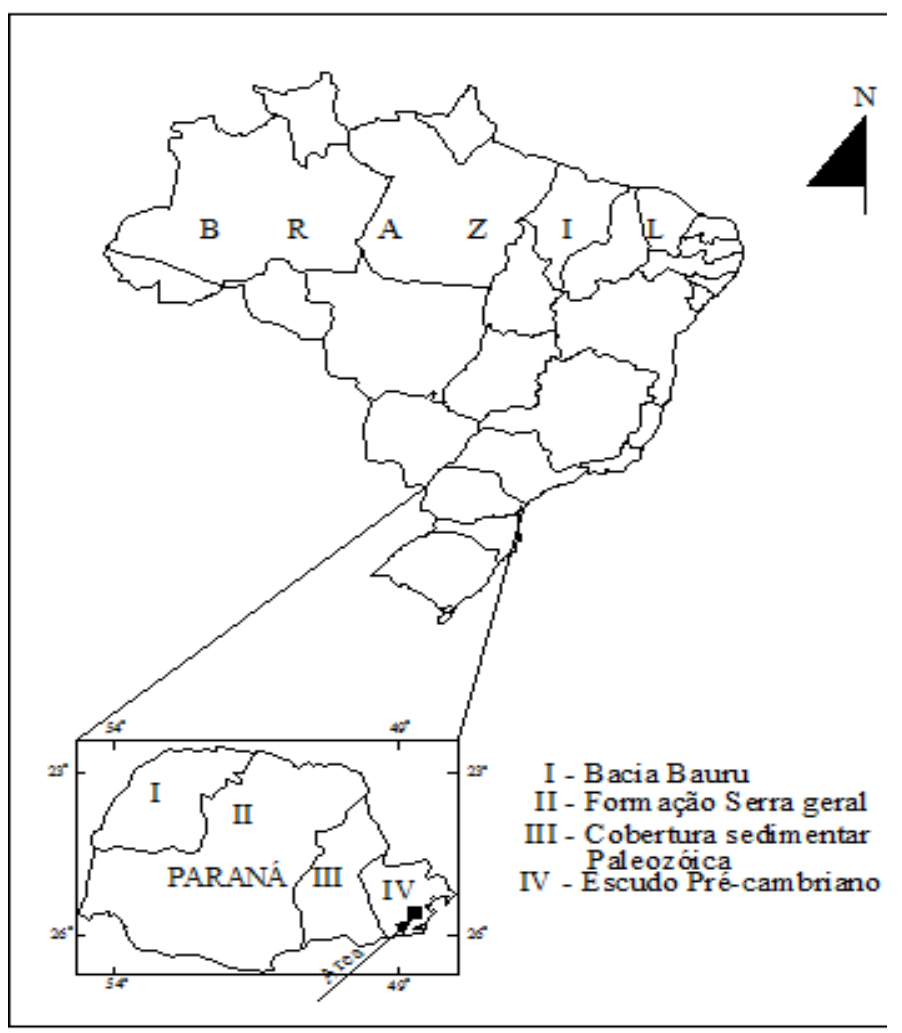

Figura 2. Localização da área de estudos e compartimentos geológicos do estado do Paraná 
BECEGATO, V. A.; MACIEL, M. M.; CABRAL, J. B. P.; CARDOSO, C. O.; SOCCOL, J. O. Monitoramento ambiental do uso e...

podocarpus além de outras e o nível inferior abrange erva, arbustos e gramíneas em geral. De acordo com a classificação de Köppen (MAACK, 1981), a região apresenta clima $\mathrm{Cfb}$ - subtropical úmido, sem estação seca. O mapa geológico está representado pela Figura 3.

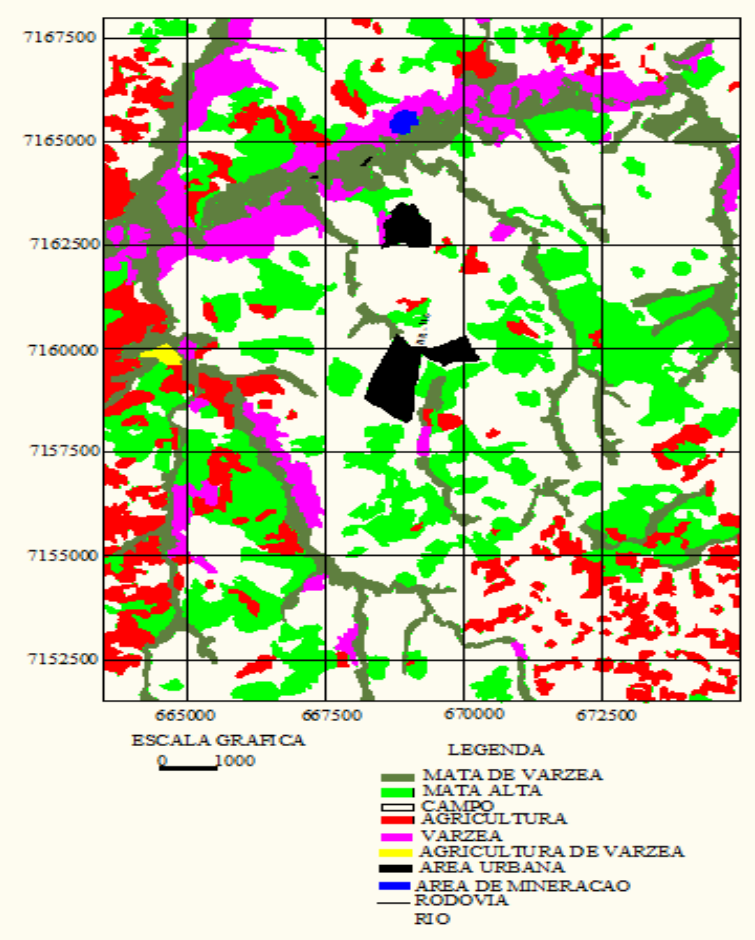

Figura 3. Mapa geológico (fonte: Becegato, 1999).

\section{MÉTODOS}

Para o estudo ambiental temporal, utilizou-se fotografias aéreas dos anos de 1952, 1962, 1980, 1996, ortofotocarta de 1980 e imagens do satélite TM-Landsat/5 órbita 220 ponto 78 ano 2001. A primeira etapa antes da fotointerpretação, foi a delimitação da área útil de cada fotografia segundo metodologia proposta por RABBEN et al. (1960), e confeccionar "overlays" de acordo com as orientações de ANDERSON (1979). Sobre as fotografias aéreas da formação do estereopar, foi realizada a interpretação do uso traçando-se sobre os "overlays" independentes das classes de uso da terra, baseando-se nos elementos convencionais de reconhecimento como tonalidade, textura, forma, arranjo espacial, tamanho e convergência de evidências.

Trabalhos envolvendo análise e planejamento ambiental, utilizam documentos de várias origens, como cartas topográficas, fotografias aéreas, imagens de satélites orbitais e dados digitais. Cada um dos produtos analógicos apresentam variações dimensionais em termos de níveis de cinza e de posicionamento relativo, segundo condições ambientais e de geometria de cena. Existe, portanto, a preocupação com a qualidade dos dados de entrada em SIG, visando a obtenção de produtos confiáveis. No caso de dados digitais uma das providências, além das correções radiométricas e geométricas de rotina, é o chamado registro da imagem, quando esta é processada e corrigida de acordo com a correspondente carta topográfica ou base cartográfica. A primeira fase do registro foi à obtenção de pontos de controle, pela definição de feições claramente identificáveis da base cartográfica - ortofoto-carta da Coordenadoria da Região Metropolitana de Curitiba, com as imagens das fotografias no monitor do computador, cujo software utilizado foi o IDRISI r. 2.0. Foram escolhidos dez pontos de controle em cada fotografia, após efetuouse a reamostragem de todos os pontos das fotografias em relação aos pontos de controle, tornando-as georreferenciadas. Feita a correção geométrica, foi possível identificar os limites em coordenadas UTM necessários para que o conjunto das fotografias formassem uma única imagem. Efetuou-se a digitalização das classes temáticas. Exportou-se os arquivos no formato DXF para o Autocad r.14 para a edição dos mapas definitivos. Para o georreferenciamento da imagens do satélite TM-Landsat/5, utilizou-se 25 pontos de controle, cujo registro empregado foi ortofoto-carta/imagem. $\mathrm{O}$ algoritimo empregado foi do vizinho mais próximo, tendo-se como objetivo manter o mais semelhante possível o valor do pixel original (CRÓSTA, 1992). Para as imagens de satélite, fez-se a composição $R G B$ das bandas 3,4 e 5 (Figura 4), objetivando buscar uma composição falsa cor, cuja coloração permitiu realçar as feições que compõem as imagens, facilitando a interpretação das mesmas. Realizou-se a classificação no modo supervisionado classificador de máxima verossimilhança do software IDRISI r.2.0, onde foi possível interferir na identificação das classes desejadas, corroborado por RODRIGUES et al. (2001). 
BECEGATO, V. A.; MACIEL, M. M.; CABRAL, J. B. P.; CARDOSO, C. O.; SOCCOL, J. O. Monitoramento ambiental do uso e...

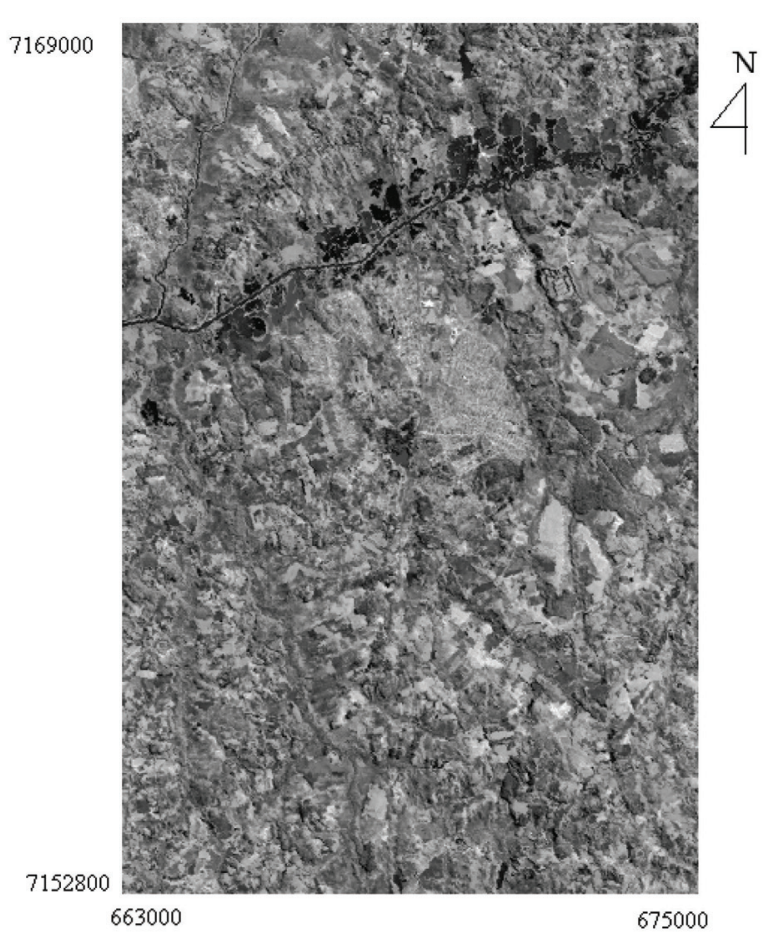

Figura 4. Imagens do TM-Landsat/5 ano 2001 composição RGB bandas 5,4 e 3 .

Para separação das classes temáticas nas imagens de satélite, utilizou-se a classificação supervisionada, que a partir do conhecimento da área ou por inferência, relacionam-se áreas das imagens com as classes de cobertura do solo que se deseja separar. Nestas áreas são selecionadas amostras de treinamento que são um conjunto de pixels considerados mais representativos das classes de interesse. Estas são portanto, definidas a priori, e o processo de classificação visa enquadrar cada pixel em uma classe. Todos os pixels das amostras de treinamento de uma dada classe constituem o conjunto de treinamento para aquela classe, o qual define um padrão de comportamento espectral, geralmente expresso em parâmetros estatísticos. O enquadramento de um pixel em cada uma das classes é feito por várias bandas utilizadas e os padrões das classes.

\section{RESULTADOS E DISCUSSÃO}

A área de estudos é composta por formas de relevos, que abrangem desde suave até fortemente ondulado, com várias microbacias, originando tributários que desaguam no coletor principal o Rio Iguaçu (Figura 1). Para a fotointerpretação, levou-se em consideração as características fisionômicas e padrões fotográficos das principais classes temáticas (Tabela 1).

Ao longo de 49 anos divididos em cinco intervalos de estudos do uso e ocupação do solo representado pelos anos de 1952, 1962, 1980, 1996 e 2001, foram encontradas nove classes temáticas, cujas áreas de ocupação dadas em hectares e percentagem respectivamente, encontram-se na (Tabela 2 ).

A classe temática que mais chama atenção é a urbana, que até o ano de 1980 era inexpressiva com $3,5 \%$ da área total, evoluindo num período de 21 anos para mais de $14 \%$. O fato mais agravante é que a expansão da cidade de Fazenda Rio Grande, está ocorrendo próximo ao Rio Iguaçú, justamente em partes constituídas por áreas de várzea, conforme pode-se constatar pelas Figuras 9 e 10. Também é possível verificar pelas referidas figuras, a passagem de um ramal de oleoduto que se estende até a refinaria de Araucária. De acordo com a Figura 10, constata-se o crescimento pela ocupação urbana próximo a um dos ramais do oleoduto. Portanto, o risco de acidentes em função da expansão da cidade pode trazer conseqüências sérias ao meio ambiente e à população.

TABELA 1. FISIONOMIA E PADRÃO FOTOGRÁFICO PARA FOTOINTERPRETAÇÃO. (ADAPTADO DE GARCIA, 1982).

\begin{tabular}{c|l|l}
\hline $\begin{array}{c}\text { CLASSES } \\
\text { TEMÁTICAS }\end{array}$ & \multicolumn{1}{|c}{ FISIONOMIA } & \multicolumn{1}{|c}{ PADRÃO FOTOGRÁFICO } \\
\hline MATA & $\begin{array}{l}\text { Floresta latifoliada subtropical, porte arbó- } \\
\text { reo alto, estratificada, cor verde escuro. }\end{array}$ & $\begin{array}{l}\text { Tonalidade cinza escuro, textura média, } \\
\text { uniforme contínua, porte arbóreo. }\end{array}$ \\
\hline CAMPO & $\begin{array}{l}\text { Campo nativo, porte herbáceo baixo ou mé- } \\
\text { dio, cor verde médio claro, alta densidade } \\
\text { de cobertura do solo. }\end{array}$ & $\begin{array}{l}\text { Tonalidade cinza-claro, claro/médio uniforme, } \\
\text { textura muita fina, estrutura maciça, porte } \\
\text { rasteiro. }\end{array}$ \\
\hline $\begin{array}{c}\text { VEGETAÇÃO DE } \\
\text { VÁRZEA }\end{array}$ & $\begin{array}{l}\text { Vegetação localizada nas planícies de } \\
\text { inundação, com espécies geralmente hi- } \\
\text { grófilas, porte herbáceo e arbustivo, cor } \\
\text { verde-escuro, alta densidade de cobertura } \\
\text { do solo. }\end{array}$ & $\begin{array}{l}\text { Tonalidade cinza-escuro e médio, textura } \\
\text { média e fina, estrutura não organizada e } \\
\text { maciça, porte rasteiro e arbustivo. }\end{array}$ \\
\hline
\end{tabular}


BECEGATO, V. A.; MACIEL, M. M.; CABRAL, J. B. P.; CARDOSO, C. O.; SOCCOL, J. O. Monitoramento ambiental do uso e...

\begin{tabular}{c|l|c}
\hline $\begin{array}{c}\text { CLASSES } \\
\text { TEMÁTICAS }\end{array}$ & \multicolumn{1}{|c}{ FISIONOMIA } & PADRÃO FOTOGRÁFICO \\
\hline REFLORESTAMENTO & $\begin{array}{l}\text { Comunidade florestal de pinus, porte } \\
\text { arbóreo alto, cor verde médio e escuro, } \\
\text { densidade de cobertura do solo médio/ } \\
\text { alto, alinhamentos retos. }\end{array}$ & $\begin{array}{l}\text { Tonalidade cinza-escuro uniforme, textura } \\
\text { fina e muito fina, telhado plano, estrutura or- } \\
\text { ganizada em alinhamentos porte arbóreo. }\end{array}$ \\
\hline
\end{tabular}

O avanço de áreas com agricultura, atingiram o índice 23,8\% em 2001, (Tabela 2), substituindo a vegetação natural composta por campo nativo e mata secundária. O problema disto, é que estas áreas encontram-se em relevo acidentado, composta por solos como os argissolos Figura 5, (PRADO, 2001). Estudos feitos na área por MACIEL (2000), mostrou que esses solos estão inseridos em relevos que vão desde ondulados a fortemente ondulados, cuja aptidão agrícola está entre $2 b c$ e $4 p$, com valores de erodibilidade (fator $K$ da equação universal de perdas de solos) na ordem de 0,033 t.h/Mj.mm.

As aptidões agrícolas das unidades de solos encontram-se na Tabela 3.
Solos com aptidão agrícola 2 bc podem ser utilizados para lavoura mecanizada, pelo fato de estarem inseridos no terço inferior da paisagem, caracterizado por relevo suave ondulado, mas que preferencialmente sejam feitas práticas conservacionistas como por exemplo terraceamento. Por outro lado, aqueles solos com nível de aptidão $4 p$, não deveriam sequer estarem desprovidos de cobertura vegetal, face serem extremamente suscepitiveis à erosão. MACIEL, (2000) salienta que solos enquadrados na categoria $4 p$, podem ter perdas de até 12 toneladas/ha/ano de solos. No que se refere aos solos enquadrados na classificação 3(b), estes possuem aptidão regular para lavoura no nível b, inapta no nível A e restrita no nível c.

TABELA 2. ÁREAS OCUPADAS EM HAE \%, RESPECTIVAMENTE PELAS CLASSES TEMÁTICAS DOS ANOS DE 1952, 1962, 1980,1996 E 2001.

ANOS FOTOINTERPRETADOS E CLASSIFICAÇÃO DAS IMAGENS DE SATÉLITE

\begin{tabular}{|c|c|c|c|c|c|}
\hline CLASSES TEMÁTICAS & 1952 & 1962 & 1980 & 1996 & $\begin{array}{l}\text { TM/Landsat-5 } \\
2001\end{array}$ \\
\hline MATA DE VÁRZEA & $\begin{array}{c}2721,6 \\
(14)\end{array}$ & $\begin{array}{c}2332,8 \\
(12)\end{array}$ & $\begin{array}{c}2449,4 \\
(12,6)\end{array}$ & $\begin{array}{c}3285,3 \\
(16,9)\end{array}$ & $\begin{array}{c}3732,5 \\
(19,2)\end{array}$ \\
\hline MATA & $\begin{array}{c}2916 \\
(15) \\
\end{array}$ & $\begin{array}{c}3402 \\
(17,5) \\
\end{array}$ & $\begin{array}{l}3363,1 \\
(17,3)\end{array}$ & $\begin{array}{c}2605 \\
(13,4) \\
\end{array}$ & $\begin{array}{l}1982,8 \\
(10,2) \\
\end{array}$ \\
\hline CAMPO & $\begin{array}{c}8942,4 \\
(46)\end{array}$ & $\begin{array}{c}10497,6 \\
(54)\end{array}$ & $\begin{array}{c}8281,4 \\
(42,6)\end{array}$ & $\begin{array}{l}5773,6 \\
(29,7)\end{array}$ & $\begin{array}{l}4412,9 \\
(22,7)\end{array}$ \\
\hline AGRICULTURA & $\begin{array}{c}2138,4 \\
(11)\end{array}$ & $\begin{array}{l}1749,6 \\
(9)\end{array}$ & $\begin{array}{c}2080,1 \\
(10,7)\end{array}$ & $\begin{array}{c}3402 \\
(17,5)\end{array}$ & $\begin{array}{l}4568,4 \\
(23,5)\end{array}$ \\
\hline VÁRZEA & $\begin{array}{r}2682,7 \\
(13,8) \\
\end{array}$ & $\begin{array}{c}1166,4 \\
(6)\end{array}$ & $\begin{array}{c}2274,5 \\
(11,7) \\
\end{array}$ & $\begin{array}{c}1652,4 \\
(8,5)\end{array}$ & $\begin{array}{c}1516,3 \\
(7,8)\end{array}$ \\
\hline $\begin{array}{c}\text { AGRICULTURA DE } \\
\text { VÁRZEA }\end{array}$ & $\begin{array}{l}38,8 \\
(0,2)\end{array}$ & $\begin{array}{l}19,44 \\
(0,1) \\
\end{array}$ & $\begin{array}{l}77,7 \\
(0,4) \\
\end{array}$ & $\begin{array}{l}136 \\
(0,7) \\
\end{array}$ & $\begin{array}{l}97,2 \\
(0,5) \\
\end{array}$ \\
\hline ÁREA URBANA & - & $\begin{array}{l}252,7 \\
(1,3)\end{array}$ & $\begin{array}{c}680,4 \\
(3,5)\end{array}$ & $\begin{array}{l}2235,6 \\
(11,5)\end{array}$ & $\begin{array}{c}2721,6 \\
(14,0)\end{array}$ \\
\hline $\begin{array}{l}\text { MINERAÇÃO } \\
\text { NA VÁRZEA }\end{array}$ & - & $\begin{array}{l}19,4 \\
(0,1)\end{array}$ & $\begin{array}{l}97,2 \\
(0,5)\end{array}$ & $\begin{array}{c}349,9 \\
(1,8)\end{array}$ & $\begin{array}{c}408,2 \\
(2,1)\end{array}$ \\
\hline REFLORESTAMENTO & - & - & $\begin{array}{l}136,1 \\
(0,7)\end{array}$ & - & \\
\hline TOTAL & 19440 & 19440 & 19440 & 19440 & 19440 \\
\hline
\end{tabular}


BECEGATO, V. A.; MACIEL, M. M.; CABRAL, J. B. P.; CARDOSO, C. O.; SOCCOL, J. O. Monitoramento ambiental do uso e...

TABELA 3. APTIDÃO AGRÍCOLA DOS SOLOS DA ÁREA DE ESTUDOS.

\begin{tabular}{l|c}
\hline \multicolumn{1}{c|}{ SOLOS } & APTIDÃO \\
\hline Argissolo Vermelho-Amarelo forte ondulado & $4 \mathrm{p}$ \\
\hline Argissolo Vermelho-Amarelo relevo ondulado & 2 " b (c) \\
\hline Argissolo Vermelho-Amarelo relevo suave ondulado & $2 \mathrm{~b} c$ \\
\hline Associação Latossolo Vermelho-amarelo relevo odulado & 2 (b) c \\
\hline Cambissolo Álico - relevo ondulado & 3 (b) \\
\hline
\end{tabular}

Observa-se pelas Figuras 8, 9 e 10, que as áreas agrícolas foram expandindo-se principalmente sobre os solos mais susceptíveis à erosão, zona Sudeste. Até o ano de 1962 (Figura 8), as áreas ocupadas por agricultura, eram caracterizadas por pequenas manchas, cujo aumento em termos de áreas contínuas, observa-se a partir de 1996 (Figura 10).

As partes ocupadas por matas, sofreram um decréscimo de $73 \%$ entre o período de 1980 e 2001 , sendo ocupadas por áreas agrícolas, cujas principais culturas são o feijão e o milho. Outra conseqüência ambiental importante, é que tais culturas utilizam inseticidas e fungicidas, que seguramente estão sendo carreados para os rios e nascentes, comprometendo a qualidade das águas superficiais e subterrâneas.

Parte da área que estava sendo ocupada por campo nativo, cuja classe foi a que teve a redução mais drástica, diminuindo de 54\% em 1962 para 22,7\% em 2001.

Áreas de mineração para extração de areia para construção civil, vêm crescendo embora não expressiva, mas pelo impacto ambiental que causam no meio ambiente. O material extraído têm como destino depósitos de materiais de construção civil da região metropolitana de Curitiba. Conforme visitas in lóco no ano de 2005 , observou-se que tanto a cidade, como as áreas para lavoura e extração de areia cresceram em relação ao ano de 2001. As áreas de mata na várzea têm aumentado, possivelmente devido a fiscalização mais intensa por parte do órgão ambiental estadual, objetivando preservar os mananciais de água.
Figura 5. Mapa de solos em nível de reconhecimento

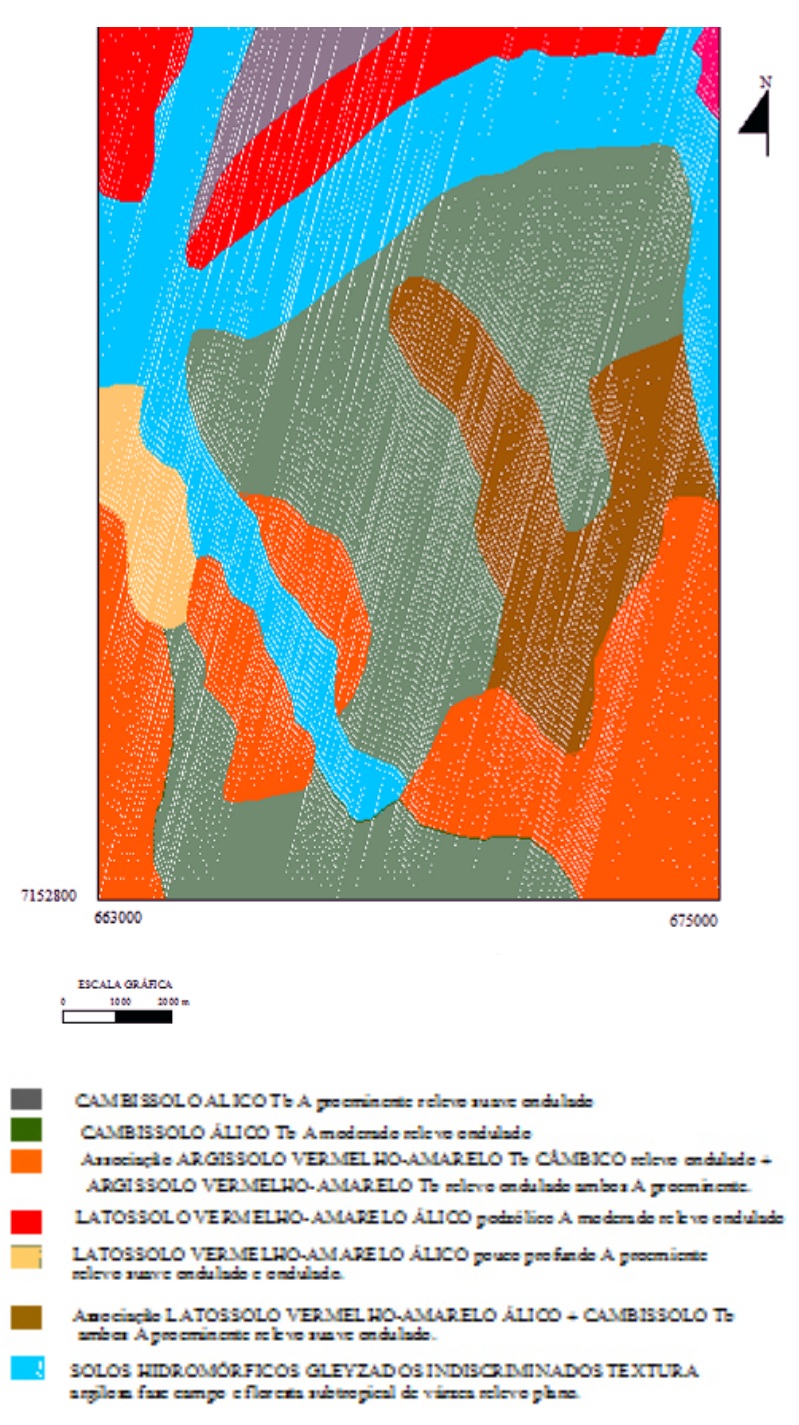

Fonte: Becegato, 1999 
Figura 6. Mapa de solos das áreas de várzea em nível de semi-

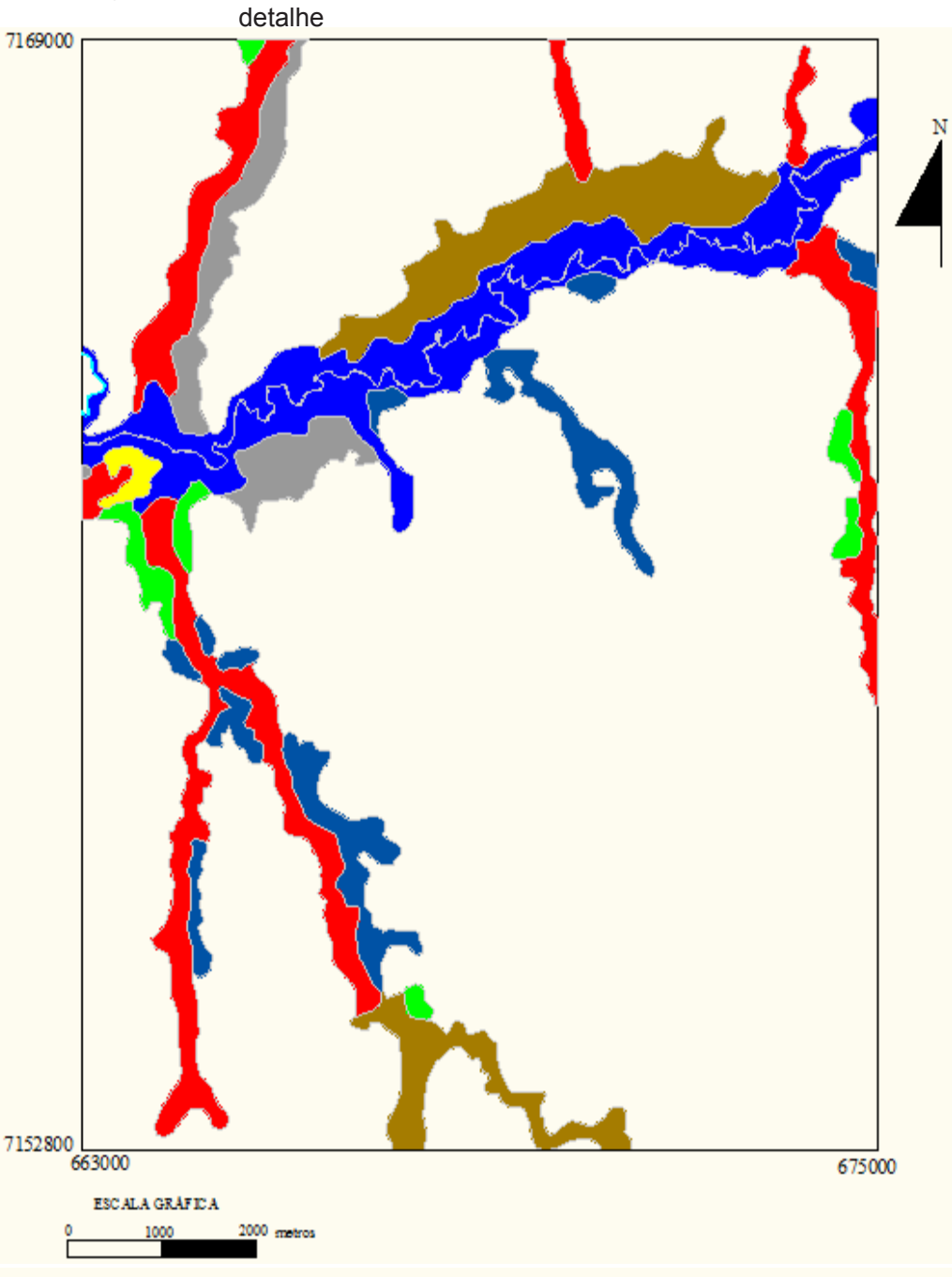

\section{LEGENDA}

HGP2 - Associação de HGP1 + Al (Solos Alvviais álicos Ta)

$\mathrm{HO} 2$ - Associação de $\mathrm{HO} 1+\mathrm{HGH} 1$

HGH1 - Glei himico allico Ta textura argilos a fase relevo

HGPI - Glei Pouco Húmifo álico Ta textura afpilosa fase

HGH3 - Associação de HGH1 + HGPl

HGH4 - Associação de HGH1 + Al (Solos Aluviai s álicos Ta)

HO1 - Solos Orgânicos álicos fase relevo plano

(mal drenado) 
Figura 7. Mapa de uso e ocupação do solo do ano de 1952.

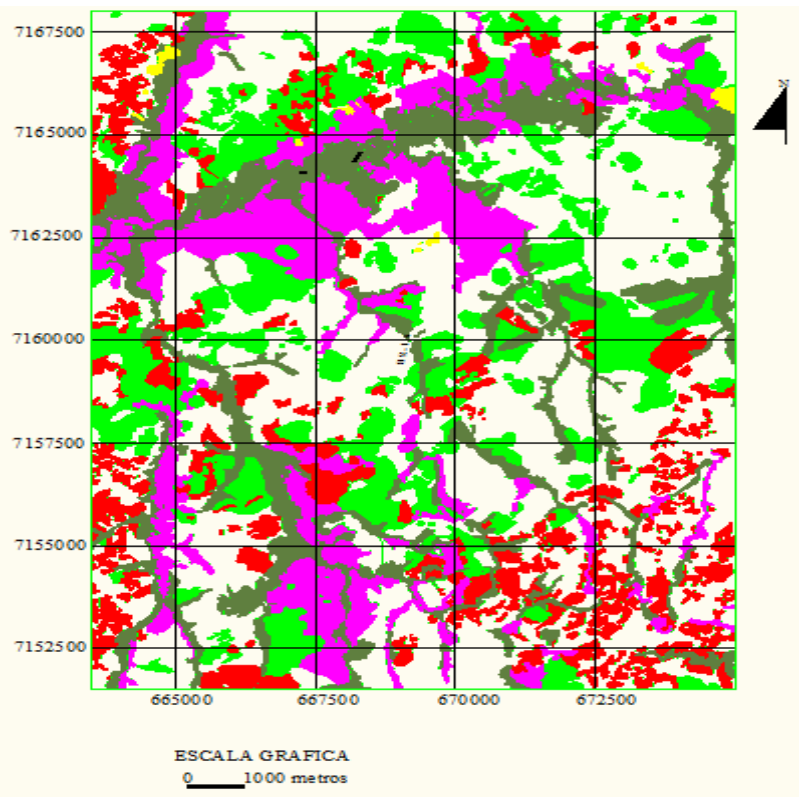

Figura 8. Mapa de uso e ocupação do solo do ano de 1962.

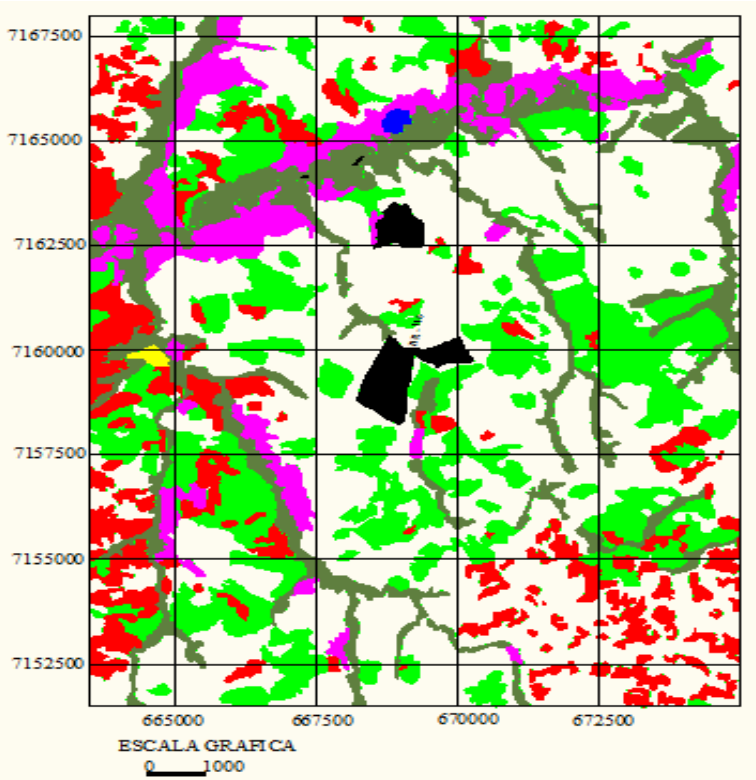

Figura 9. Mapa de uso e ocupação do solo do ano de 1980.

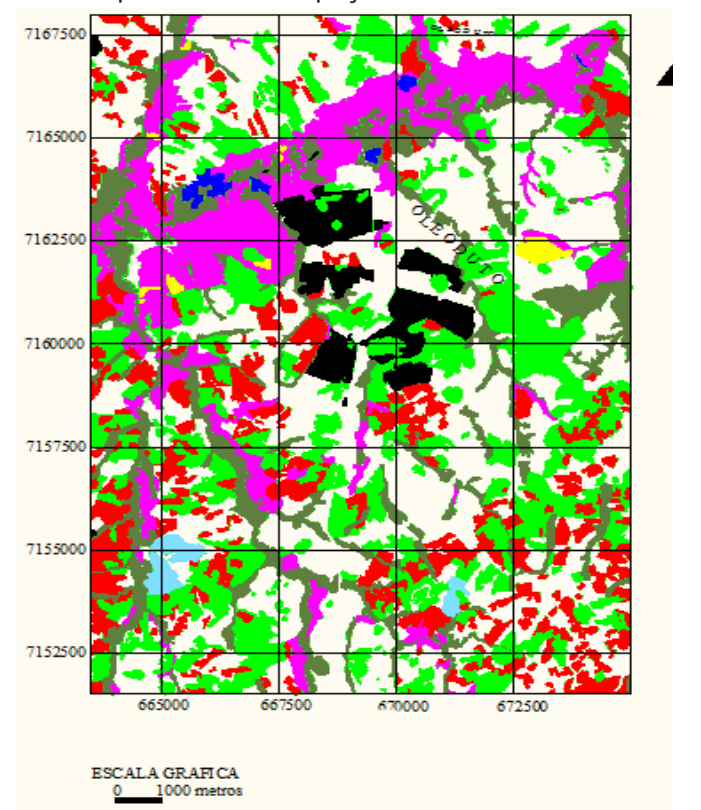

Figura 10. Mapa de uso e ocupação do solo do ano de 1996.

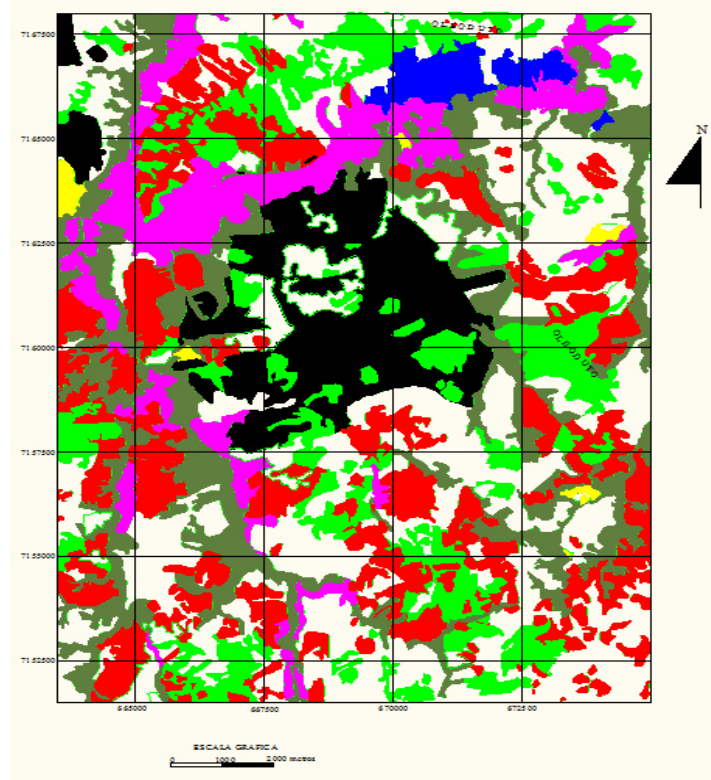

LEGENDA

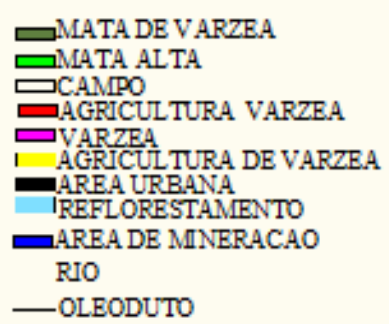


BECEGATO, V. A.; MACIEL, M. M.; CABRAL, J. B. P.; CARDOSO, C. O.; SOCCOL, J. O. Monitoramento ambiental do uso e...

\section{CONCLUSÕES}

A expansão antrópica da área urbana intensificouse significativamente entre 1980 que era de $3,5 \%$, para 14\% em 1996;

O Avanço da ocupação antrópica está muito próximo das margens do Rio Iguaçu.

A ocupação da atividade agrícola em 2001 chegou a 23,5 da área;

As áreas de agricultura estão avançando sobre os solos inseridos principalmente em áreas declivosas, notadamente os argilosos;

A passagem de um ramal de oleoduto no perímetro urbano da cidade de Fazenda Rio Grande é um grande risco tanto ambiental como antrópico;

O uso de pesticidas nas áreas agrícolas podem estar contaminado os mananciais de água;

O tratamento dos dados em ambiente de SIG permitiu separar, quantificar e comparar as classes temáticas das diferentes datas estudadas.

A interpretação visual das imagens de satélite do ano de 2001 foi facilitada pelo comparativo da fotointerpretação das classes temáticas obtidas do ano de 1996, utilizada como verdade terrestre, embora houvesse intervalo de cinco anos entre as duas cenas.

JÚNIOR (1999), utilizando imagens do TMLandsat/5 combinado com a banda $\mathrm{C}$ do Radarsat em estudos geo-ambientais, observa que a interpretação visual das imagens em composições coloridas, conduz a um estudo da distribuição espacial das classes e suas associações onde visualmente percebe-se os tipos mais ou menos distintos e as variações tonais.

A assinatura espectral da área urbana foi a de meIhor separabilidade, representado pela cor rosa próxima ao centro da imagem (Figura 4), seguido pelas áreas de mata de várzea e mata, embora tenha havido certo grau de mistura nestas assinaturas, fato contornado pela utilização das fotografias aéreas do ano de 1996 em par esterioscópico, cujo procedimento também foi adotado pôr RIBEIRO (1997). JUPIASSÚ (1993) e GONG e DUNLOP (1991), observaram para a importância da homogeneidade da seleção das amostras, pois todas as informações na hora da classificação da cena vêm das amostras e portanto estas devem representar fidedignamente cada classe amostrada.

\section{REFERÊNCIAS}

ANDERSON, J.R. Sistema de classificação do uso da terra e do revestimento do solo para utilização com dados de sensores remotos. Rio de Janeiro: IBGE, 1979. 80p.

ARONOFF, S. Geographic Information System: A management perpective. Ottawa, Canadá:WDL Publications, 1993.

ASSAD, M.L.L. Uso de um sistema de informações geográficas na determinação da aptidão agrícola de terras. R. bras. C. Solo, Campinas, 19:133-139, 1995.

BECEGATO ,V.A. Análise de agrupamentos em ambiente de geoprocessamento para discriminação de unidades fisiográficas. Curitiba-PR 115p. Mestrado (Universidade Federal do Paraná).

BIGARELLA, J.J., SALAMUNI, R. Características texturais dos sedimentos da bacia de Curitiba. Bol. da Universidade do Paraná (7). (1ª parte): 1962, p.1-164.

BURROUGH, P. A. Principles of Geographical Information Systems for Land Resources Assessment. Oxford: Calrendon Press, 1986. 94p.

CANEPARO, S.C. Análise da dinâmica espacial da ocupação antrópica em Paranaguá/PR (1952-1996), através do uso de sistema de informações geográficas. R. RA'E GA, Curitiba, n. 4. p.111-130. 2000. Editora da UFPR.

CRÓSTA, A.P. Processamento digital de imagens de sensoriamento remoto. Campinas, SP: IG/UNICAMP. 1992, 170p

DANGERMOND, J.A. Classification of softwares components commoly used in geographic information systems. International Journal of Geographic Information Systems, 1987.

EKSTRAND, S. Thematic mapper in tropical forest inventaries. A comparison with Landsat MSS data, panchromatic aerial photography and color infrared aerial photografy. Proccedings of the twentieth international symposium on remote sensing of environment v.3:1085-1101. Kenya, 1986.

EMBRAPA. Levantamento de Reconhecimento dos Solos do Estado do Paraná. Londrina, IAPAR/SUDESUL, 1984. v.2 (Boletim Técnico no. 52).

GARCIA, G.J. Sensoriamento remoto - Princípios e Interpretação de imagens. São Paulo, Nobel, 357p. 1982.

GONG, P., DUNLOP, J.D. Comments on the skidmore and turner supervised non parametric classifier. Photogrammetric engineering \& remote sensing. v.57, n.10, 1991.

JÚNIOR, H. F. da SILVA. Combinação de imagens RADARSAT e Landsat-5 para fins de mapeamento Geo-Ambiental. Curitiba-PR. 1999. 120p. (Mestrado - Universidade Federal do Paraná). 
BECEGATO, V. A.; MACIEL, M. M.; CABRAL, J. B. P.; CARDOSO, C. O.; SOCCOL, J. O. Monitoramento ambiental do uso e...

JUPIASSÚ, A. Cartas imagem básica e temática folhas Teresópolis e Anta escala 1:50.000. Anais do XVI Congresso brasileiro de cartografia, v.3:541-543. Curitiba, 1993.

MAACK, R. Geografia física do estado do Paraná. 2.ed. Rio de Janeiro, José Olympio, 1981, 442p.

MAACK, R. Mapa geológico do Estado do Paraná. Escala 1.750.000. Serviço de Geologia do Instituto de Biologia e Pesquisas Tecnológicas. 1953.

MACIEL, M.M. Aplicação da equação universal de perdas de solos (USLE) em ambiente de geoprocessamento e sua comparação com aptidão agrícola. Curitiba-PR. 2000. 76p. (Mestrado - Universidade Federal do Paraná).

MINEROPAR - Mapa geológico do Estado do Paraná. Escala 1.650.000. Curitiba-PR, 1989.

PRADO, H. DE. Solos do Brasil: genêse, morfologia, classificação e levantamento. 2. ed. Revisada e ampliada. 220p. 2001.

RABBEN, E.L., CHALMERS JÚNIOR, E.L., MANLEY, E., et al. Fundamental of photointerpretation. In: American Society of Photogrammetry. Manual of photographic interpretation. Washington, 1960. Cap. 3, p.100-66.

RIBEIRO, S.R.A. Aplicação de técnicas de geoprocessamento no estudo de solos e confecção de banco de dados relacional digital do município de Palotina-PR. Curitiba, 1997. 155p. (Mestrado - Universidade Federal do Paraná).

RODRIGUES, J.B.T., ZIMBACK, C.R.L, PIROLI, E.L. Utilização de sistema de informação geográfica na avaliação do uso da terra em Botucatu(SP). R. bras. Ci. Solo, 25:675-681, 2001.

VEDONELLO, R., MATTOS, J.T. Uso de teledecção na compartimentação fisiográfica para obtenção de um zoneamento geotécnico de múltiplo uso em regiões litorâneas. Anais do simpósio Latino Americano de Percepciõn Remota, v.5: 473-479. Cuzco-Peru, 1991. 